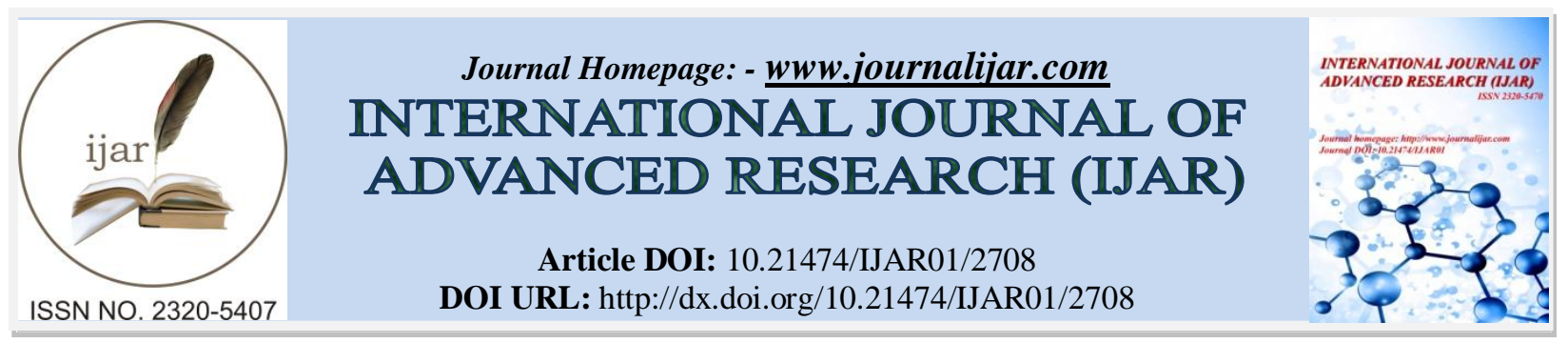

RESEARCH ARTICLE

\title{
INFLUENCES OF HYSTERECTOMY ON BODY COMPOSITION.
}

Dr. Arpita Mandal (Nandi).

Department of Anthropology, Narasinha Dutt college, 129, Belilious Road, Howrah.

\section{Manuscript Info}

Manuscript History

Received: 31 October 2016

Final Accepted: 01 December 2016

Published: December 2016

Key words:-

Hysterectomy, body composition and weight gain

\section{Abstract}

Body composition and pattern of weight gain changes with menopause. This study attempts to compare these changes among two groups of women. Group 1: women who gain spontaneous or natural menopause and Group 2: women who undergo hysterectomy and thus their menopause onsets. This study suggests that hysterectomy has a strong influence on postmenopausal weight gain and other body composition characteristics. Hysterectomized women gained a significant $8.7 \mathrm{~kg}$ on average as compared to $5.3 \mathrm{~kg}$ in women experiencing spontaneous menopause. This also indicate that hysterectomy significantly influences a greater risk of bringing in "android" type of fat distribution in women.

Copy Right, IJAR, 2016,. All rights reserved.

\section{Introduction:-}

Menopause is the transition during which women experience symptoms that vary widely. It is the permanent cessation of menstruation which results from the loss of follicular activity of the ovaries. This physiological development brings about the end of women's reproductive function. (Som et al,2012). The variations are the result of the major hormonal changes together with the effect of socio-demographic and other reproductive factors (Dasgupta et al, 2015). Hysterectomy is one of the most frequently performed surgeries in women of reproductive age. Hysterectomy not only ends one's reproductive life but brings in many adverse effects in women in later life (Kirchengast et al, 2000). The women mostly undergo this surgery to get relief from a range of symptoms like, pelvic pain, irregular bleeding, urinary symptoms, fatigue and other related symptoms (Carlson et al, 1994). However, the most commonly faced problems after hysterectomy are: hot flushes, depression, a lack of sexual interest and significant weight gain (Kjerulff et al 1993, Kjerulff et al 2000, and Juarbe et al 2006). In spite of the diverse effects of hysterectomy on well being there are only a few studies considering the influence of hysterectomy on postmenopausal body composition. Hysterectomy is an artificial kind of menopause bringing in abrupt physiological changes in women. This is in contrast to the gradual physiological changes that comes in women experiencing spontaneous menopause. Body composition can be used as a useful marker for assessing the adiposity or fat distribution of an individual. Fat centralisation occurs in menopausal and postmenopausal phases and studies have proved its relation to the menopause or years since the onset of the menopause (Toth et al., 2000). There are some studies that attempted to proved that fat mass increase and centralisation is related only to age without any influence of the menopause (Pasquali et al., 1994) and there is already evidence of fat centralisation in premenopausal women (Pascot et al., 1999).

The present study attempts to assess the composition differences between hysterectomized women and women with spontaneous or natural menopause. 


\section{Material and Methods:-}

A total of 137 women aged between 39-58 (mean 50.7) were considered for the study. All women were postmenopausal at the time of study and they had gained menopause at least one year prior to the study. All the women were chosen from the Middle Income Group, Housing Complex of Kalindi Housing Estate, Kolkata-89. The women were exclusively Bengali Hindu women and were home-makers. This was chosen to maintain an endogenous group for the study. They were divided into two groups: Group 1 comprised of 81 women aged between 47-58 years (Mean $=51.4+2.7$ ) who attained spontaneous or natural menopause at least one year prior to the study, Group 2 comprised of 56 women aged between 39-48 years (Mean=43.7 \pm 3.2) who had undergone hysterectomy at least one year prior to the study.

A structured questionnaire was used to gather information on the menopausal history and other details regarding menopausal problems. The women were also asked to report weight changes since menopause. Body weight before the onset of menopause were recorded in both the groups of women. For Group 1 women body weight before menopause was based on self-report. While for women of Group 2 body weight was determined using clinical records of weight status before hysterectomy. Data obtained with the questionnaire included demographic characteristics, reproductive history (menstrual characteristics, pregnancy history, infertility treatment, contraceptive use), medical and gynecological history, gynecological history of mothers and sisters, menopausal symptoms, and lifestyle characteristics (smoking, alcohol consumption, limited diet history, physical activity).

Women were queried about their usual frequency of strenuous and moderate physical activity over the past 2 years, and over the past year at follow-up. Strenuous activity was defined as activity that increases one's heart rate or makes one breathe heavily, such as running or sports at a competitive level. Moderate physical activity was defined as activities, such as brisk walking or sports at a social level. Women also reported trends in their weight during adulthood (weigh less than as a young adult, weight was stable $\pm 10 \mathrm{kgs}$ throughout adulthood, weigh more than as a young adult, or weight fluctuates with gains and losses of $>10 \mathrm{kgs}$ on two or more occasions) and their perception of how their weight changed in the year between baseline and 1 year follow-up. A consent form was signed by women undergoing hysterectomy allowing access to the medical records related to their surgery.

\section{Statistical Analysis:-}

Baseline characteristics of the women undergoing hysterectomy and the control women were compared using chisquare tests or Fisher's exact test for categorical variables and Student's $t$ tests for continuous variables. Comparisons of changes in weight and BMI between baseline and follow-up were evaluated with analysis of variance (ANOVA), controlling for baseline values of these variables. Multiple linear regression was used to estimate change in weight or BMI by hysterectomy status, controlling for the characteristics. Variables evaluated as potential confounders in the multivariable linear and logistic regression models included age, body weight, marital status, educational level, number of full-term pregnancies, smoking status, current alcohol consumption, physical activity and weight change as an adult.

\section{Evaluation of Body Composition:-}

Body composition was estimated through the circumferential and girth measurements of the Mid- upper arm, Chest, Waist and Hip along with Body weight and Stature. These measurements were selected to find out the distribution of fat in the various parts which further help in determining the "android" or the "gynoid" distributions.

Results:-

Table 1:- Characteristics of Women with Hysterectomies and Control Women.

\begin{tabular}{|l|l|l|l|l|}
\hline \multicolumn{1}{|c|}{ Characteristics } & \multicolumn{2}{c|}{ Women with Hysterectomies ( N=56) } & \multicolumn{2}{c|}{ Control women (N=81) } \\
& Mean & \multicolumn{1}{c|}{ SD } & Mean \\
\hline Age in years & 43.7 & 3.2 & 51.4 & 1.9 \\
\hline $\begin{array}{l}\text { Number of } \\
\text { pregnancies }\end{array}$ & 1.8 & 1.7 & 2.3 & $\%$ \\
\hline Marital status & $\mathrm{N}$ & $\%$ & $\mathrm{~N}$ & 76.8 \\
\hline Married & 36 & 64.2 & 62 & 9.6 \\
\hline Unmarried & 08 & 14.3 & 08 & 13.6 \\
\hline Divorced & 12 & 21.6 & 11 & $\%$ \\
\hline $\begin{array}{l}\text { Educational } \\
\text { Qualification }\end{array}$ & $\mathrm{N}$ & $\%$ & $\mathrm{~N}$ & \\
\hline
\end{tabular}




\begin{tabular}{|l|l|l|l|l|}
\hline Higher secondary & 05 & 9.4 & 14 & 17.6 \\
\hline Graduate & 38 & 67.3 & 40 & 49.5 \\
\hline Post Graduate & 11 & 19.7 & 16 & 19.3 \\
\hline Others & 02 & 3.6 & 11 & 13.6 \\
\hline $\begin{array}{l}\text { Use of } \\
\text { Contraceptions }\end{array}$ & $\mathrm{N}$ & $\%$ & $\mathrm{~N}$ & $\%$ \\
\hline Oral Pills & 47 & 83.7 & 36 & 43.9 \\
\hline IU objects & 03 & 5.7 & 09 & 11.3 \\
\hline Smoking Habits & $\mathrm{N}$ & $\%$ & $\mathrm{~N}$ & $\%$ \\
\hline Non smoker & & 94.1 & & 97.3 \\
\hline Regular smoker & & 2.1 & & 0.3 \\
\hline Former smoker & & 1.8 & & 1.4 \\
\hline Alcohol habits & $\mathrm{N}$ & $\%$ & $\mathrm{~N}$ & $\%$ \\
\hline Never & 24 & 43.7 & 47 & 58.4 \\
\hline Occasional & 21 & 37.4 & 27 & 33.6 \\
\hline Regular & 11 & 18.9 & 07 & 8.1 \\
\hline Physical activity & $\mathrm{N}$ & $\%$ & $\mathrm{~N}$ & $\%$ \\
\hline None & 19 & 34.6 & 19 & 23.7 \\
\hline Moderate & 24 & 41.7 & 44 & 54.3 \\
\hline Regular & 11 & 19.5 & 15 & 18.9 \\
\hline Occasional & 02 & 4.2 & 03 & 3.1 \\
\hline $\begin{array}{l}\text { Weight Changes } \\
\text { After menopause }\end{array}$ & $\mathrm{N}$ & $\%$ & $\mathrm{~N}$ & $\%$ \\
\hline$>$ 5Kgs & 03 & & & 14 \\
\hline 5-10kgs & 17 & 5.1 & 46 & 57.5 \\
\hline 10-15kgs & 31 & 54.7 & 16 & 19.4 \\
\hline$<15 \mathrm{kgs}$ & 05 & 8.6 & 05 & 5.9 \\
\hline
\end{tabular}

\section{Analysis of Table 1:-}

The details of the characteristics of the women undergoing hysterectomies and the control women are presented in Table 1. Women undergoing hysterectomies had fewer children as compared to the women who had natural menopause. Educational status were higher in case of hysterectomised women (67.3\% graduates ) as compared to the women of the control group ( $49.5 \%$ graduates) . Compared with the control group, the women who had hysterectomies were more likely to be ahead in consuming oral contraceptive pills (83.7\%), smoking habits $(2.1 \%$ regular smokers as compared to $0.3 \%$ in control group) and consuming alcohol (18.9\% in comparison to $8.1 \%$ in control group). It is also clear from the table that hysterectomised women were less physically active in comparison to the control group. $41.7 \%$ women of group 1 were moderately physically active, whereas as good as $54.3 \%$ women of group 2 were into moderate physical activity.

Table 2:- Weight and Body Mass Index (BMI) Characteristics Comparing Women with Hysterectomies and Control Women

\begin{tabular}{|l|l|l|l|l|l|}
\hline Characteristics & \multicolumn{2}{|c|}{$\begin{array}{c}\text { Women with Hysterectomies } \\
(\mathrm{n}=56)\end{array}$} & \multicolumn{2}{c|}{ Control women (n=81) } & P value \\
& Mean & 6.8 & 27.8 & 7.1 & 0.008 \\
\hline $\begin{array}{l}\text { BMI before } \\
\text { menopause }\end{array}$ & 29.6 & 7.2 & 28.3 & 7.8 & $0.003^{* *}$ \\
\hline $\begin{array}{l}\text { BMI after } \\
\text { menopause }\end{array}$ & 31.7 & 1.7 & 0.9 & 2.2 & $0.06^{* *}$ \\
\hline Change in BMI & 1.9 & 17.5 & 72.6 & 19.3 & $0.01^{* *}$ \\
\hline $\begin{array}{l}\text { Weight before } \\
\text { menopause }\end{array}$ & 79.4 & 19.2 & 75.4 & 21.2 & $0.005^{* * *}$ \\
\hline $\begin{array}{l}\text { Weight after } \\
\text { menopause }\end{array}$ & 82.3 & 5.9 & 5.3 & 3.7 & $0.07^{* *}$ \\
\hline $\begin{array}{l}\text { Change in } \\
\text { weight }\end{array}$ & 8.7 & & & \\
\hline
\end{tabular}




\section{Analysis of Table 2:-}

In this table data on weight and BMI at baseline and follow-up is presented. The mean BMI was quite high for both the women undergoing hysterectomy and the control group (31.7 and $28.3 \mathrm{~kg} / \mathrm{m}^{2}$, respectively) and more than half of the women with hysterectomies were obese. The change in BMI is significant for both the groups of women (Group 1: $1.9 \mathrm{~kg} / \mathrm{m}^{2}$ and Group 2: $0.9 \mathrm{~kg} / \mathrm{m}^{2}$ ). The mean changes in weight were $8.7 \mathrm{~kg}$ and $5.3(p<0.001)$ for women with hysterectomies and control women, respectively. Thus hysterectomised women show significant higher values for both BMI and Weight gain characteristics.

Table 3:- ANOVA analysis.

\begin{tabular}{|l|l|l|l|}
\hline Analysis of variance & df & Mean & F value \\
\hline Weight gain & & & \\
\hline Hysterectomy & 1 & 144.7 & $3.7^{* *}$ \\
\hline Stature & 1 & 79.6 & $2.4^{*}$ \\
\hline Chronological age & 1 & 143.6 & $3.1^{* *}$ \\
\hline Time since menopause & 1 & 3.9 & $0.2^{* * *}$ \\
\hline BMI & & & \\
\hline Hysterectomy & 1 & 19.1 & $3.6^{* *}$ \\
\hline Stature & 1 & 60.3 & $2.9^{*}$ \\
\hline Chronological age & 1 & 18.3 & $3.1^{*}$ \\
\hline Time since menopause & 1 & 57.3 & $2.1^{* * *}$ \\
\hline
\end{tabular}

$*=\mathbf{p}<0.05, * *=\mathbf{p}<0.01, * * *=\mathbf{p}<0.001$

Analysis of Table 3:-

The significant differences in postmenopausal weight gain between women with natural menopause and hysterectomised women were according to the results of ANOVA, not due to the insignificant group differences in stature or chronological age. It is also distinct from the table that the more the time since menopause the more the significant increase in weight and BMI in both the groups of women.

Table 4:- Circumferential measurements and hysterectomy.

\begin{tabular}{|l|l|l|l|l|l|}
\hline Characteristics & \multicolumn{2}{|c|}{$\begin{array}{c}\text { Women with Hysterectomies } \\
(\mathrm{n}=56)\end{array}$} & \multicolumn{2}{c|}{ Sontrolled women $(\mathrm{n}=81)$} & $\mathrm{t}$ \\
& Mean & 4.8 & Mean & & \\
\hline $\begin{array}{l}\text { Mid-upper arm } \\
\text { circumference }\end{array}$ & 34.6 & 32.3 & & $2.83^{* *}$ \\
\hline Chest girth & 98.5 & 7.3 & 96.6 & 6.4 & $2.09^{* * *}$ \\
\hline Waist girth & 91.8 & 5.7 & 90.7 & 4.9 & $1.67 \mathrm{~ns}$ \\
\hline Hip girth & 96.3 & 3.7 & 94.7 & 4.3 & $2.14^{* *}$ \\
\hline $\begin{array}{l}\text { Thigh } \\
\text { circumference }\end{array}$ & 46.2 & 2.9 & 44.8 & 3.5 & $0.81 \mathrm{~ns}$ \\
\hline Chest Breadth & 36.2 & & & & $2.05^{* *}$ \\
\hline
\end{tabular}

$* *=\mathbf{p}<0.01, * * *=\mathbf{p}<0.001, \mathrm{~ns}=$ not significant

\section{Analysis of Table 4:-}

This table helps us to understand the difference in body composition especially fat distribution in both the hysterectomised women and women with spontaneous menopause. The hysterectomised women show higher values for the arm, chest and hip measurements. Hysterectomised women show more values for the android type of fat distribution as compared to the women with spontaneous menopause.

\section{Discussion:-}

Women undergo critical changes for body weight regulation on attainment of menopause and during the post menopause phase of their life (Wang et al 1994,Wise et al 2005). Earlier studies have reported that women tend to gain weight of around 5 to $10 \mathrm{kgs}$ in average with the attainment of menopause (Kjerulff et al 1993, Brown et al 1998, Johnson et al 2006). This increase in weight is caused by decreased physical activities accompanied by the unchanged eating behavior with increasing age ( Rebuff- Scrive et al, 1985,1986; Hartman et al 1995, Kirchengast et al 1997a). The "gynoid" type fat distribution ( larger amount of fat in the hips and thigh) changes into a more 
"android" type ( increase in the central body fat, like chest and abdomen) bringing in the "metabolic syndrome" . This constitutes a risk for the development of cardiovascular diseases, hypertension, hyperlipidaemia, diabetes and the like ( Ley et al 1992, Kirchengast et al 1997a, Mandal et al 2013).

This study suggests that hysterectomy has a strong influence on the weight gain and body composition of postmenopausal women. In this study, a population of women aged 39-58 years ( mean age being 50.7) showed differences in risk factors between the women undergoing hysterectomy and control women that are consistent from Table 2 to Table 4. Women of Group 1 undergoing hysterectomy had lesser number of pregnancies ( Mean 1.8) as compared to the Group 2 women who had experienced spontaneous menopause( Mean 2.3) as revealed in Table 1. The same Table 1 also shows that Group 1 women were more on Oral contraceptive pills ( 83.7\%) in comparison to Group 2 women( 43.9). Educational level of the women also had an impact on hysterectomy, Group 1 women had higher percentage of graduates ( 67.3\%) whereas lesser women in Group2 (49.5\%) as seen in Table 1. As evident from Table 2, BMI of the hysterectomised women were significantly higher, in comparison to the control women with natural menopause $(\mathrm{p}<0.001)$. Most hysterectomised women were already obese with their mean BMI being 31.7 whereas the mean BMI of the control group was 28.3. Moreover, women of group 1 are more younger ( Table 1: mean age $=43.7$ years ) than the women who reached natural menopause ( mean age $=51.4$ ). This is a very important point to be discussed further as hysterectomised women are forced to experience menopausal changes at least about 7 years earlier. This change also comes to them abruptly, giving no time to the body to adjust gradually to the changing physiology within as a result of the change in Hormone type and Hormone level. Weight gain was a common occurrence in all (Group1 women increased by a mean of $8.7 \mathrm{kgs}$ and Group 2 women $5.3 \mathrm{kgs}$ ), the difference of increase in body weight between the two groups is shown to be significant at 0.001 level ( Table 2). Marital status, educational levels, smoking and drinking habits were also potential cofounders in weight gain in the women participating in this study (Table 1). Following Table 3, this study suggest that hysterectomy has a strong influence on postmenopausal weight status and body composition characteristics. The ANOVA analysis show that the more the time since menopause the more the significant increase in weight and BMI in both the groups of women. The Table 4 analysis clearly show that hysterectomised women have higher values for the measurements like mid-upper arm circumference (MUAC), chest girth, hip girth and chest breadth. The differences in these measurements were highly significant between the two groups of women under study ( $p<0.001$ to 0.0001 level). These measurements represent the "android" type fat distribution. Waist and thigh region do not show any significant difference between the two groups.

\section{Conclusion:-}

Hysterectomy occurred in most of the women at a comparatively earlier age in women as compared to women attaining menopause naturally. Hence, the study suggests that younger women are abruptly exposed to an older age experience. This may be one of the important reasons for exposure to stress factors and depression brought about by the fact that the removal of the uterus signals a "loss of womanhood and attractiveness". This psychological stress may again boost up the increased food intake in these women. Hysterectomy also brings in android fat distribution in women suggesting it to be a big risk factor. Weight distribution were in consistence to the prevalence of obesity in women in other populations (Ogden et al 2008, Hedley et al 2004).

\section{Limitations of the Study:-}

The sex-hormonal levels and their differences could not be studied . Dietary information was limited so it was not possible to assess the extent of weight gain due to diet pattern. Diet questions were on the intake of general categories of food such as red meat, poultry products, fish, vegetables, fruit and fruit juices but insufficient detail to quantify the total energy intake. The physical activity was based on self report.

\section{References:-}

1. Brown WJ, Dobson AJ, Mishra G. 1998. What is a healthy weight for middle aged women? Int J Obes Rel Metab Disord. 22: 520-528.

2. Carlson KJ, Miller BA, Fowler FJ. 1994. Jr The Maine Women's Health Study: I . Outcomes of hysterectomy.Obstet Gynecol. 83:556-565.

3. Carlson KJ. 1997. Outcomes of hysterectomy. Clin Obstet Gynecol. 40: 939-946.

4. Dasgupta D, Karar P, Ray S, Ganguly N. 2015. Menopausal Symptoms and Its Correlates: A Study on Tribe and Caste Population of East India. Curr Gerontol Geriar Res.30(9): 847-867. 
5. Dasgupta D, Pal B , Ray S. 2015. Factors that discriminate age at menopause: A study of Bengali Hindu women of West Bengal. American Journal of Human Biology ,27(5):710-715.

6. Hartmann BW, Kirchengast S, Albrecht A, Metka M, Huber JC. 2009. Symptomatology of postmenopausal syndrome. Gynecol. Endocrinology. 9: 247-252.

7. Hartmann KE, Ma C, Lamvu GM, Langenberg PW, Steege JF, Kjerulff KH. 2004. Quality of life and sexual function after hysterectomy in women with preoperative pain and depression. Obstet Gynecol. 104:701-709.

8. Juarbe TC, Gutiérrez Y, Gilliss C, Lee KA.2006. Depressive symptoms, physical activity, and weight gain in premenopausal Latina and white women. Maturitas. 55:116-125.

9. Johnson N, Barlow D, Lethaby A, Tavender E, Curr E, Garry R. 2006. Surgical approach to hysterectomy for benign gynaecological disease. Cochrane Database Syst Rev. 2:CD003677.

10. Kiechengast S, Gruber D, Sator M, Hartmamm B, Knogler W, Huber J. 1997a. Menopause dependent changes in female fat patterning estimated by dual energy x-ray absorptiometry. Annals of Human Biology. 29: 45-54.

11. Kirchengast S, Gruber D, Sator M, Huber J. 2000. Hysterectomy is associated with postmenopausal body composition characteristics. J Biosoc Sci. 2: 37-46.

12. Kjerulff KH, Langenberg PW, Rhodes JC, Harvey LA, Guzinski GM, Stolley PD. 2000. Effectiveness of hysterectomy. Obstet Gynecol. 95:319-326.

13. Kjerulff K, Langenberg P, Guzinski G.1993. The socioeconomic correlates of hysterectomies in the United States. Am J Public Health. 83:106-108.

14. Ley LA, Hillis SD, Marchbanks PA, Koonin LM, Morrow BA, Wilcox LS. 1997. Hysterectomy surveillanceUnited States 1980-1993. MMWR CDC Surveill.Summ. 46: 1-15.

15. Mandal (Nandi) A, Das Chaudhuri AB, Mandal GC. 2013. Significant impact of fertility status on body fat among the urban Bengalee women from Kolkata, West Bengal, India. The journal of humanities and Social Science. 112: 186-190.

16. Pascot,A, Lemieux S, Lemiex I, Prud'hommed D, Tremblay A, Bouchard C, Nandeau A, Couillard C, Tchemnof A, Bergeron J, Despres JP. 1999. Age-related increase in visceral adipose tissue and body fat and the metabolic risk profile of premenopausal women. Diabetes Care. 22: 1471-1478.

17. Pasquali R, Casmiri F, Labate AM, Tortelli O, Pascal G, Anconetani B, Gatto MR,,Flamia R, Capelli M, Barbara L.1994. International Journal of Obesity and Related Metabolic Disorder. 18: 614-621.

18. Rebuff-Scrive M, Enk L, Crona N. 1985. Fat cell metabolism in different regions in women : Effects of menstrual cycle, pregnancy and lactation. J.Clin. Invest. 75: 1973-1976.

19. Rebuff-Scrive M, Eldh J, Hafstorm LO, Bjorntrop P.1986. Metabolism of mammary abdominal and femoral adipocytes in women before and after menopause. Metabolism. 35:792-797.

20. Som N, Ray S. 2012. Menopause-specific quality of life of urban women in West Bengal, India. Menopause Int. 18(3): 99-105.

21. Toth MJ, Tchernof A, Sites CK, Poehlman ET. 2000. Effect of menopausal status on body composition and abdominal fat distribution. International Journal of Obesity and Related Metabolic Disorders. 24: 226-231.

22. Wang Q, Hassager C, Ravn P, Wang S, Christiansen C. 1994. Total and regional body composition changes in early postmenopausal women: age related or menopause related? American Journal of Clinical nutrition . 60: 843-848.

23. World Health Organisation 1994. Quality of Life Assessment, International Perspective, Berlin: Springer.

24. Wise LA, Palmer JR, Spiegelman D. 2005. Influence of body size and body fat distribution on risk of uterine leiomyomata in U.S. black women. Epidemiology. 16:346-354. 